\title{
Cloud Computing: Overview and its Deployment Model
}

\author{
Prateek .M ${ }^{1}$, Rahul.R ${ }^{2}$, Arman .S \\ ${ }^{1,2,3,}$ Department of Electronics Engineering, NMIMS University MPSTME, Shirpur Maharashtra, India
}

\begin{abstract}
:
We live in the era of gigantic complexity. With the daze elevation in technology, the IT infrastructure has remoulded to the core. However, in the fullness of time the epoch of cloud computing is now arising also acknowledged as on-demand computing. It provides marketability, fidelity, coherence, high-performance and adequately low-lying cost conceivable way out as compared to dyed-in-the-wool infrastructure .Aloft the internet, it is the technology yielded in the form of service and these services are furnished with the hardware system in the data centres. This paper gives the meticulous outlining for cloud and focuses on the primarily outlook of Cloud Computing. In the long run, this paper comes to light to render the service modal, types of cloud computing : IaaS, PaaS, SaaS, ways of cloud computing as well as advantages and disadvantages of Cloud Computing. The future of this technology is at top of ladder. It is the next generation and can be of tremendous value to the worldwide companies.
\end{abstract}

\section{INTRODUCTION}

In this up to the minute developments in the arena of Information Technology which is not only just moving, thinking, sharing, processing and making money but also renders the human race haystack of enjoyment by propounding the every folks life tranquilizing within the state of every individual's mind. With the aid of their convenience and comfort relish-gusto and in the end meeting up to their daily needs. Cloud Computing is certainly one of the revolutionary technology in the kingdom of Information Technology and is now changing the perspective of enterprises throughout the world. This technology has the proficiency to ingress the run-of-the-mill. It is justifying surpassingly Eye-Catching to the impoverished IT departments, which wanted to come across with prominent services under thrust.

\section{BACKGROUND}

Since its inception in the early midnineties cloud computing has become a mainstay for modern work and leisure. The origin of cloud computing can be traced back to early net work schematics where the appearance of overlapping server icons resembled the billows of cloud. Soon a cloud-like shape came to be synonymous with areas on a network .In the beginning there were computers \&software's, whenever the company wants to utilize the software for its business it needs to purchase the software completely and install it in local computer. Whenever new features are added in software, the company needs to upgrade in order to keep up to date. Growing software demanded more computing power .This means for every two years the hardware needs to be updated in order to support software loaded with features due to the highly lack of resources. Many small enterprises never update even up to time. These also included cash to purchase new versions of software [1] .Also training the people about latest feature and 3increasing the hardware as per software demands. Large Corporation who had good resources kept progressing and small of small business left behind. Then in the fullness of time came cloud. Usually experts around the world preferred the internet as cloud. Millions of servers from across the globe are connected to cloud including the computer. So let's assume the cloud to be virtual space which can be accessed only though internet connection. Software's that were earlier distributed as product to individual and business are now available on cloud and user can excess through the browsers[2]. Anyone can use the software through login by knowing the password, which can be obtained through paying a minimal fee based on the requirements. The company can choose their subscriber only to feature what they use. Whenever new features are added to software it made available to all across the globe .Users can also store the data on cloud using the same products. Cloud offers unlimited cloud capacity that helps the consumer to purchase store based on the usage .In addition the data is also backed up in the server across the globe so there is no need to worry about hardware failures or maintenance cost.

In the recent years due to innovative technology, any users can access the cloud from any device from around the world[3]. This enables the users to access the software through multiple devises called thin clients. This way the cloud helps small business to gain the maximum by utilizing very less resources. 
Cloud Computing is on the hype right now .It is very big and is growing bigger every day.

\section{TYPES OF CLOUD COMPUTING}

III.1 Private Cloud- In a private cloud environment the same capabilities are controlled by enterprise in their own-hosted environment for their own use only. Private clouds are more expensive but offer a trade-off of higher levels of security. The trade-off is strictly a business decision by the cloud buyer but in general, most people use public cloud today for test, development, application etc.

III.2 Public Cloud- The public cloud is connected to the public internet for anyone to leverage .Public cloud provider makes resources available to the public for free. Anybody can leverage the resources for their own use, which is unrestricted as well[4]. The public cloud is connected to the public internet for anyone to leverage. Public clouds tend to be cheaper because they are using shared infrastructure and more suited for application whose information is private.

III.3 Hybrid Cloud- Hybrid cloud marries the advantage of both approaches and its fundamentally ensuring that the workloads are managed by the most appropriate infrastructure. According to one survey $66 \%$ of enterprises plan move to hybrid clouds within the next 4years[5]. The real strength of hybrid cloud is that they pull together element traditional It, private cloud or public cloud so that the users do not know where the service comes from and who owns it as well as maintains it.

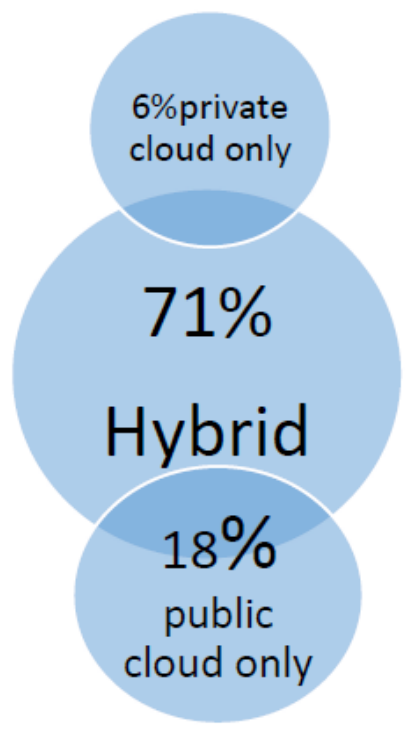

Fig.III.4: 95\% of Respondents are using Cloud [5]

III.4 Virtual Private Cloud -This is another kind of hybrid cloud known as virtual private cloud. This is the private section of the service providers cloud or data centre cloud within a cloud but the key distinction is that it is effectively yours to manage, as you like. This means it advantages of the private cloud but without the costs of owning the infrastructure.

\section{DEPLOYMENT MODEL OF CLOUD COMPUTING}

As categorized, there are three bottom line cloudcomputing models according to their abstraction level and provide resources and provide. These models provides some sort of IT resources to the user. These models categorize the Cloud Computing in various types of services.

\section{IV.1 INFRASTRUCTURE AS A SERVICE}

Cloud provider will not only own the equipment, which is providing the infrastructure resources, but they are also responsible for management, operation and maintenance of the resources. These are all typical infrastructure resources. In IaaS model, every consumer can straight away use the infrastructure elementals such as storage, network, firewall etc.

IaaS resolves around moving our core infrastructure equipment's to the cloud. No longer do companies need to buy and maintain Telephone system, servers and firewalls, on their premises [6]. They can now purchase the servers like any utility. This provides enormous benefits to the company but is likely to result in any lower equipment for IT staffing.

This cloud service allows us to create a new infrastructure easily and efficiently without having to purchase any physical hardware. This saves our time and money.

\section{IV.2 Platform as a Service}

PaaS enables customers who are mainly developer's build their application without assuming the capital and resource cost that they had to purchase and maintaining it on their own infrastructure. Developers using PaaS do not need to worry about maintaining or configuring structure for developments so they are truly able to focus on what matters to the PaaS model renders boon to the developer in form of develop complement software [7].

\section{IV.3 Software as a Service}

Provides customer with software application on demand over the internet the customer does not need to purchase hardware required to deploy and operate this application. Software as a Service sales in 2015 reached 20 billion\$[8]. Like other, SaaS is hosted at the cloud provider so the customer does not need to purchase hardware required to deploy and operate this application and is expected to be doubled in 2020 . Customer Relationship 
Management continues to be the largest market for SaaS. Example- CRM, Office and Communication applications [9].

\section{ADVANTAGES AND DISADVANTAGES OF CLOUD COMPUTING V.1 ADVANTAGES OF CLOUD COMPUTING}

-Software Updates: - The service provider will carry out all maintenance and updates.

-Flexible: - Emailing file to each individual can be avoided instead send a web link to all recipients through email-id.Resources can be increased or reduced depending upon workload. It is easy to scale up cloud capacity, drawing on the service's remote servers.

- Control Costs: - It helps in controlling costs. Fees is based on consumption payments can be made monthly or yearly [10].

-Collaboration:-Employees can synchronise up and work wherever they are. Cloud based workflow and file sharing apps help them updates in real time and gives full visibility of collaboration.
-Secure:- All corporate data is stored in a central location. As a result it minimises risk of data loss. The data stored on cloud can be accessed by the user on any device by secured sign-in process. So none of the data is lost or stolen from cloud.

\section{V.2 DISADVANTAGES OF CLOUD COMPUTING}

-Network Based-

It is completely network based which is a problem in general because that also means that is quite hard to keep it safe.

-Quality of Service:-

The Quality of Service is a key decisive factor in the adaptability of cloud network. Quality of service is yielded by allotting resources in the cloud network.

-Separation of Data:-

In Cloud Environment, data is not specifically isolated. When the arrival of specific data needs to be fetched, the problem starts to come to light as it been allocated throughout the cloud network[11]

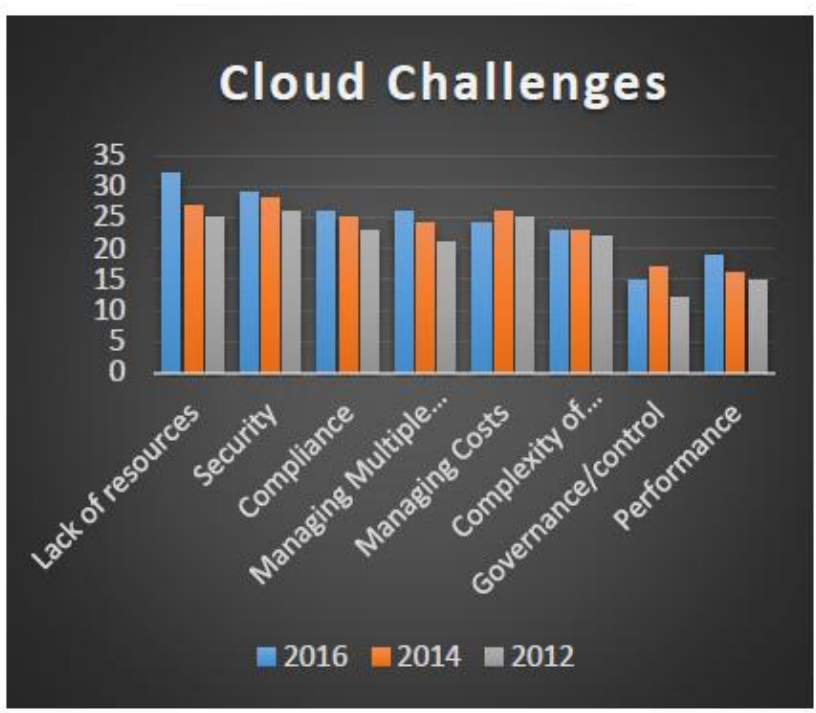

Fig.V.3: Cloud Challenges 2016 vs 2014 vs 2012[12].

\section{CONCLUSION}

Cloud Computing is the most promising prototype for the emerging technology that solves many problems and irritations so that to scrutinize on our business and to not running on accounting legal or marketing development. It is one of the key reasons to save money, time and resources on noncore business functions with no real business benefits. Through web services, it renders easy ingress to highly performance computing resources as well as storage infrastructure. Cloud services provide data protection, which is much more robust so that even a natural disaster that wipes out entire data centre would not be radically cause to lose anything. To put it all bluntly, the endowment to leverage almost everything to drive down the value makes cloud computing more alluring option for commercial business.

\section{REFERENCES}

[1]. R. Maggiani; (2009), "Cloud computing is changing how we communicate," 2009 IEEE International Professional Communication Conference, IPCC 2009, Waikiki, HI, United states ,pp 1, 19-22 July.

[2]. Jack Schofield. Wednesday 17 June 2009 22.00

BST, 
http://www.guardian.co.in/technology/2017/ jan/27/cloudcomputingjack-schofield.

[3]. Dikaiakos, M.D; Katsaros, D.; Mehra, P.; Pallis, G.; Vakali, A.; (2010), "Cloud Computing Distributed Internet Computing for IT and Scientific Research".Vol.13 ,pp 10, Sept.-Oct. 2009.

[4]. Janakiram MSV Cloud Computing Strategist; (2010), "Demystifying the Cloud An introduction to Cloud Computing",Version1.0- March.

[5]. Peter Mell, Timothy V Grance "The NIST Definition of Cloud Computing "NIST Special Publication 800-145(2011).

[6]. A.Srivastava,Wednesday,29Jan2011, 22.00 IST

[7]. H. Stockinger. (2013). "Defining the grid: a snapshot on the current view". The Journal of Supercomputing, (1):3-17

[8]. Website:-http://diversity.net.nz/wpcontent/uploads/2011/03/UnderstandingtheCloud-Computing-Stack.pdf

[9]. SM. Hashemi,Cloud Computing, AK. Bardsiri, ARPN Journal of Systems and Software (02011-2014 AJSS Journal.

[10]. Liang-Jie Zhang and Qun Zhou, CCOA: Cloud Computing Open Architecture 2015 IEEE International Conference on Web Services, 2009.

[11]. Grobauer, B.; Walloschek, T.; Stocker,E.;(2016), “Understanding Cloud Computing Vulnerabilities",5487489 searchabstrSecurity \& Privacy, IEEE, Vol 9 , pp 50.

[12]. RightScale 2016 State of the Cloud Report. 